\title{
Cognition, Learning and European Regional Growth: An Agent-Centred Perspective on the "New" Economy
}

\author{
Paul Tracey, Gordon L. Clark and Helen Lawton Smith \\ Rothermere American Institute, School of Geography and the Environment, University of \\ Oxford, South Parks Rd, Oxford, OX1 3TG, United Kingdom
}

Contact Email: paul.tracey@geog.ox.ac.uk Tel: 44-1865-282722 Fax: 44-1865-271940

\begin{abstract}
Quintessentially a US phenomenon, the information and knowledge economy (IKE) combines regional clusters of innovation with new and sophisticated forms of intellectual and finance capital. Regions such as Silicon Valley in California and Route $128 / 495$ in Boston have excelled in technologically sophisticated, knowledge-based industries such as telecommunications, information technology and software development. They have won praise for their innovativeness, entrepreneurship and phenomenal growth, and have been central to the remarkable renaissance of the US economy over the last two decades. Although some point to similar regions in Europe, there is widespread concern that Europe cannot match the innovativeness of the US. For those European economies struggling to adjust to global competition, the IKE is seen as the panacea. It is regarded as a proven recipe for all places and sectors, with the potential to remedy structural weaknesses that have become ever more apparent in a world subject to globalisation, increased international competition, and technological change. This paper begins with the IKE as a source of wealth creation and competitive advantage. Building on previous work, we suggest an agent-centred perspective for understanding economic systems and behaviour that stresses the significance of cognition and learning for innovation while making the connection between organizations and their environments. As represented by Silicon Valley, the IKE is complex and multi-faceted, and cannot be transposed easily between cultures: place-specific features of social and spatial organization underpin the IKE, acting as resources for actors and promoting collective action. Finally, we draw together the implications of our approach for European regional development, both in the European Union and in the accession countries of central and eastern Europe.
\end{abstract}

Acknowledgements. This paper was prepared for presentation at the Annual Meeting of the Association of American Geographers, Los Angeles (March 2002). It is draws upon an EC $5^{\text {th }}$ Framework project on Regional Adjustment Strategies to Technological Change in the Context of European Integration (RASTEI) (Contract HPSE-CT-1999-00035) funded through the "Key Action on Improving and the Socio-economic Knowledge Base" programme. Supplementary support was provided by the UK ESRC Future Governance programme co-ordinated by Professor Edward Page. We would also like to thank Merridy Wilson research assistance. 


\section{Introduction}

Since the early 1980s, the economic performance of continental EU economies has been generally modest. Whether measured by rates of unemployment, rates of employment growth or economic growth, Europe has consistently under-performed compared to its immediate Atlantic competitor. Although the reasons for their contrasting fortunes are complex and multi-faceted, the emergence of the so-called information and knowledge economy (IKE) in the US and its limited development in much of the EU appears to have been an important factor. At the Lisbon summit of European leaders in March 2000, the need for greater dynamism and entrepreneurship within Europe was widely noted. Delegates focused on the "paradigm shift driven by globalisation and the new knowledge economy" and recognised that a "radical transformation of Europe's economy and society" is needed if it is to keep pace with the US. With the likely accession of a number of nearneighbours from central and eastern Europe to the EU, these issues are ever more important for the future development and social cohesion of Europe. European policy makers take these concerns seriously; unless the EU improves its competitive position, it will be unable to sustain its social and political objectives.

The development of the IKE and the increasing importance of the global economy suggest that we are moving into a new phase of economic development. According to Teece (2000), the growth of the IKE can be explained by reference to characteristics such as the rapid and cost-effective exchange of information, the expansion of markets for different types of products, the deregulation of product and labour markets, and the increased flow of financial assets around the world. At its core, however, is 'the development and astute deployment and utilization of intangible assets of which knowledge, competence, and intellectual property are the most significant' (p.3). Furthermore, the knowledge economy is believed to have a distinctive geography regional clusters of innovation, technology, and human and social capital, as illustrated by Silicon Valley, Rt 128/495 Boston, and (in the UK) Cambridgeshire and Oxfordshire (Lawton Smith 2001). This point was also made by Antonelli (2001) who noted that 'the regional and technological concentration of innovation activities' suggests the growing importance of endogenous forces of growth (set against conventional expectations that export-led growth is the model for all nations). 
For some, new kinds of knowledge have replaced the long-established sources of competitive advantage that dominated mainstream economic thought since the publication of Adam Smith's (1776) The Wealth of Nations: endowments of natural resources, concentrations of capital, the availability of labour, and economies of scale. See, for example, Blackler (1995). The veracity of these claims is not entirely clear; knowledge was, of course, central to virtually all kinds of economic activity long before the notion of the IKE entered social scientific discourse, and most work has always relied upon intuitive, tacit and unarticulated stores of knowledge (Ackroyd, Glover, Currie and Bull 2000). In our view, the significance of the IKE cannot be adequately understood just in terms of the importance or otherwise of knowledge per se, or because it appears to be a distinctive geographical form, or because the industries normally associated with it rely upon forms of knowledge that are fundamentally different or more esoteric from that of other industries. ${ }^{1}$ The essence of the IKE, and what makes it a very real phenomenon which has profoundly affected rates of labour productivity, innovation and economic growth, are the distinctive ways in which knowledge is created and disseminated between constituent actors, and the accompanying changes to the organization of firms, industries and regions.

Recent years have seen terms such as 'the learning region' and 'the learning organization' become important in the lexicon of social scientists concerned about competitiveness and competitive advantage. In many respects these concepts form the basis of our understanding of the IKE, although their use is by no means confined to the study of knowledge-based industries. Instinctively, we are uncomfortable with this terminology. We begin with the assumption that cognitive capacity is the domain of human beings; organizations and regions do not possess consciousness. To pretend otherwise may be to retreat unwittingly into the dogma of neo-classical economics, the shackles of which have been only recently tempered. Nevertheless, we also assume that agents cannot be considered without also taking into account the contexts in which they operate. Firms, regions and their associated institutions are crucial for individual and collective learning and for innovative behaviour in general. Specifically, they provide

\footnotetext{
${ }^{1}$ Ackroyd, Glover, Currie and Bull (2000) argue that 'that knowledge - and more importantly conceptions of knowledge - are intimately related to particular interests and relations of power' (p.289). It is the process by which knowledge is constructed and used, rather than the nature of a particular body of knowledge, which influences behaviour.
} 
structural and procedural mechanisms and channels of communication that enable the collation, manipulation, analysis, and dissemination of knowledge and information. More importantly, through the use of routines and conventions, we believe that organizations and regions can institutionalise ways of thinking, thereby exerting a powerful influence on behaviour (Levitt and March 1988). Any theory of learning and innovation must be able to accommodate the interaction between individual, group, organizational and regional or societal levels of action that this implies. However, despite the endurance and persistence of many institutions and decision-making routines, we do not believe that they have an existence independent of the actors who sustain them, or that they necessarily overwhelm individual consciousness so that agents are oblivious to their existence. We consider agent-environment interaction to be a two-way process, one in which agents may have the capacity to manipulate their environments for their own purposes just as their surroundings may directly affect agent behaviour (Clark, Tracey and Lawton Smith 2001; Tracey, Clark and Lawton Smith 2001).

The next section of the paper outlines our views about the nature of cognition, a subject which has been much-neglected within economics and geography but one which we believe to be crucial for understanding innovation and economic development. In section 3 we outline a tripartite conception of learning based on the work of Argyris and Schon $(1978,1996)$ and which forms the theoretical basis for our arguments. This is followed by our model of innovation with respect to the IKE which seeks to describe and explain the complex interactions between the relevant cognitive, institutional and organizational factors. In section 5 our model is discussed in the context of European regional development. In doing so we are mindful that that Europe is a very different economic environment to the US. Finally we discuss the prospects for, and limits to, knowledge-based activity in Europe.

\section{The Nature of Cognition}

The capacity to think and learn is surely a most remarkable characteristic of human beings, and as such it has long been a focus of study for social scientists. The doctrine of rationality has formed a central component of this body of knowledge. Indeed, it has underpinned much social scientific thought related to the nature of the self, society and 
culture since Spinoza (1632-77) and Leibnitz (1646-1716) (Sedgwick 1999). At the beginning of the 21st century, its influence remains strongest in economics, where the view of agents as rational, utility maximising subjects continues to dominate the mainstream of the subject (cf. Hodgson 1996). According to the theory of subjective utility (SEU theory), decision-making comprises three basic elements (Simon 1987). (1) Choices are made among a fixed set of alternatives all of which are known to agents; (2) agents are aware of the probability distributions with regard to the outcome of each option; and (3) choices reflect agents' desire to maximise the expected value of a given utility function. This approach, rooted in positivism and scientism, assumes that learning occurs experientially through trial and error and that knowledge consists of accumulated discrete events each of which are observable. The systematic nature of behaviour implies that patterns of knowledge can be discerned and measured. Proponents of this approach argue that it is possible to measure and explain behaviour with a view to making empirical generalizations.

Previously, we used Simon's $(1956,1997)$ notion of 'bounded rationality' as the basis of our objections to the rational paradigm, and Simon's work remains a powerful reference point for understanding cognition and decision-making (Tracey, Clark and Lawton Smith 2001). By his logic, the ability of individuals, groups or firms to behave in rational ways is constrained by (1) limited resources, interests, knowledge; (2) limited cognitive capacity, and (3) the environment in which they operate. Decision-makers do not have all of the relevant information available, nor do they have the cognitive capacity to process such information in the needed SEU 'scientific' fashion. Because agents make decisions knowing only some of the likely consequences of their actions, they 'satisfice' rather than optimise or maximise; they choose an option which they believe will at least meet a priori specified criteria. This is true of apparently straightforward decisions, but is especially the case in decisions which have a strategic dimension: the more important the decision to be made, the greater the number of factors to be considered, and the more farreaching (but ill-defined) the consequences (Clark and Marshall 2002). ${ }^{2}$

\footnotetext{
2 Another, perhaps more profound, reason for supposing that rationality is a spurious characteristic to attribute to agents is that rationality is a cultural conception of meaning which is rooted in the social and economic development of Western society, and the product of a specific set of historical circumstances (Sahlins 1976). In view of this, Lave (1998) argued that 'it is difficult to defend claims for the universality of
} 
Whilst acknowledging the limitations of the human mind, in other ways the bounded rationality model assumes that agents' behaviour is more sophisticated than the rational paradigm implies. This is perhaps most evident when agents deal with situations where outcomes and goals are incommensurable. In circumstances where decisions are likely to result in both positive and negative consequences, or where different interest groups are likely to be affected in different ways, no optimal choice can be made. The complexity of all but the most basic problems means that agents rely heavily on heuristics, or rules of thumb, for making inferences and ultimately decisions about their worlds. Heuristics are perhaps best described as the generic application of rules to situations subject to the limitations of time, knowledge and cognitive capacity; they are particularly important when the range of available options is unclear, and where information about the options themselves (and their likely outcomes) is limited (Gigerenzer and Todd 1999). Considered in this way, heuristics are essentially strategies to simplify, systemise and economise on decision-making.

Although the heuristics employed differ between cognitive tasks and adaptive problems (adaptive problems tend to use emotions rather than cognitive mechanisms to aid decision making), they each share three common building blocks: they search, they stop search and they make a decision. Searching involves the investigation of (1) alternatives (the choice set) and (2) cues (for evaluating the alternatives). Common search schemas include random search, ordered search (for example, considering cues in relation to their validities), and search imitation (which allows humans to learn quickly from others of where to look and what to look for). For adaptive tasks, emotions such as fear and disgust can narrow choice sets dramatically. According to Simon (1955), the search process is stopped when a course of action is found which matches or exceeds the aspiration level (this is the essence of his 'satisficing' concept). For Gigerenzer, however, several (possibly competing) goals with different aspiration levels are likely to co-exist in any given situation and so search stops 'as soon as the first cue that favors one alternative is found' (2001 p. 44). A decision or inference is made when the search process has ended.

\footnotetext{
"rational" modes of good thinking as a scientific yardstick with which to evaluate situated cognitive activities... constructing research in terms of mythological views of scientific thought insures blindness to questions of the structuring of everyday activities themselves' (p.174).
} 
When making important or strategic decisions, agents endeavour to weigh up the consequences of particular alternatives. For less significant decisions, however, the difficulties inherent in this task means that attempts to weight alternative factors or to develop a common currency to facilitate comparison are limited.

Agents do not, of course, exist in isolation. The organizational, social and geographical contexts in which they operate provide powerful cues for behaviour in the form of norms and customs, which are themselves underpinned by shared beliefs and meaning. The heuristics that agents develop to make inferences about their worlds are often transposed onto the structures and modes of operation of organizations and other institutions that comprise their environment. These institutional heuristics help to further divide, routinize and bind together the decision-making process in order to make it manageable. As Morgan (1997) points out, divisions of labour serve not only to facilitate the allocation of human and other resources but also create 'a structure of attention, information, interpretation, and decision-making that exerts a crucial influence on an organization's daily operation' (p.79). This allows agents to 'take advantage of the structure of the information in the environment to arrive at meaningful decisions' (Gigerenzer and Todd 1999, p.28). In other words, agents rely on institutions, at varying levels of aggregation, as mechanisms to assist decision-making and in order to 'enact' their environments.

\section{A Model of Learning}

In explaining learning and innovation in the IKE, many scholars in geography and in economics have moved away from models of SEU rationality, arguing that economic activity is a socially embedded process that takes place within institutional and cultural frameworks (Grabher 1993). The IKE tends to be considered in the context of 'innovation systems' which manage the interaction of production units with their environments (Dosi 1988; Malecki 1997; Kaufman and Todtling 2000), and which vary significantly between countries (Whitley 1992) and regions (Cooke and Morgan 1997). Many of the factors that enable production units to harness knowledge are thought to be found in the social and institutional contexts in which they are located, rather than within production units themselves. Innovation systems store knowledge independently of individuals, and 
facilitate learning and development through its collection, organization and dissemination. The role of institutions is considered to be particularly important because they underpin behaviour by forming the boundaries for agents' options and choices through 'situated patterns of meaning and action' (Hasselbladh and Kallinikos 2000 p.698) which manifest themselves in the form of social regularities, customs and norms.

In this respect, or so it is argued, the competitive advantage of production units located in knowledge-based environments develops in ways that are self-reinforcing. Innovative capacities evolve and adapt in response in order to accommodate particular technologies or sectors. Clusters are formed when knowledge 'spills over' from large corporations and/or universities, spawning closely-related satellite ventures in associated sectors. The degree of interaction between the local academic community, businesses and financial institutions is believed to be an important building block for local innovation systems. Such interaction facilitates technological communication at the local and national levels (Castells and Hall 1994; Antonelli 2000).

These insights provide a more complete picture through which to view economic activity and represent significant progress in relation to our understanding of regional economic development. Perhaps its most meaningful contribution has been to illustrate the role and importance of institutions for social and economic systems, and for learning and innovative behaviour. As this new model has emerged, however, the role of agents appears again to have been marginalized. In place of super-rational and optimising agents, we have an institution-centred approach with individuals, their behaviour, their goals and their beliefs more or less taken for granted. While knowledge and learning form central components of this approach, emphasis is placed on the role and importance of institutions in shaping cognition and action, with tacit rather than formal knowledge the primary means through which competitiveness is sustained.

Tacit knowledge reinforces the apparently pre-determined nature of behaviour because it is spread through habits and routines (which are the basis for social regularities, customs and norms), rather than through cognitive processes which require deliberation. As Clark, Tracey and Lawton Smith (2001) point out, 'the possibility that the behaviour, aims and aspirations of individuals might be influenced by social factors other than institutions is not considered... [and in] many instances, the possibility that there might be 
conflict between individuals and institutions is glossed over, as are the mechanisms whereby individuals are shaped by social cultures that change over time' (p.9-10). By highlighting the role of tacit knowledge and routinised behaviour in innovation systems, many neo-institutionalists imply that agents are essentially receptors, and that they simply respond to their environments with little or no capacity for strategic choice. Thus in many ways, and despite its welcome critique of SEU rationality, such an approach is less of a departure from neo-classical economics and rationalist modes of thinking than it might appear. In this paper, we redress this imbalance by placing cognition at the centre of our analysis of learning and innovation whilst acknowledging the role of inherited institutions as resources and constraints on action. The challenge we face is to illustrate that the development of industries and regions is essentially a product of the thought and action of the agents that create and sustain them.

The rapidly expanding literature on learning is indicative of the considerable interest which the subject engenders, and its presumed importance for innovation and economic performance. We begin with the model created by Argyris and Schon (1978, 1996) that we have adapted slightly so that it is compatible with our views about cognition, and the role of institutions, and so that it considers learning in the context of the region as well as the context of the firm. Human activity takes place on many different levels and consists of many different layers. Argyris and Schon describe this as a 'ladder of aggregation', with individual agents forming the building blocks for broader units of analysis: small groups of agents, departments, functional divisions, whole organizations, external organizations such as suppliers and distributors, and ultimately other organizations and institutions which embody regional, national and supranational social and economic systems. These layers interact in complex ways, and agents often operate on several of them simultaneously, and move frequently between them. This involves great complexity, which is magnified because each layer may have its own political "culture" with its own (albeit related) values, norms and objectives. Both the layers, and the formal and informal structures and channels of communication that sustain them, comprise the learning system within which agents operate. These systems are created and sustained by agents; agents can reinforce existing patterns of learning, they can facilitate their restructuring, and they can defect from their expectations. 
One of the strengths of this model is that it is agent-centred. In other words, it assumes that organizations depend on individuals to learn. This does not imply that organizations contain the sum of the knowledges of their members. The learning process is part of a complex learning cycle that consists of a number of different stages. For agents to take a proactive role in the learning process they must (1) detect error in the operation of the learning systems of which they are part; (2) search for the sources of error and devise new strategies designed to correct them; before (3) evaluating the results of the strategies that were implemented - actions obviously related to the search processes, noted above. At this point, to the extent that learning may have occurred, it has done so at an individual level. To realise learning at higher levels of aggregation, such as the firm or the region, agents must convince others of their 'discoveries, inventions and evaluations' and ultimately 'reform' the formal and informal practices of the institutions of which they are part. Organizational learning can be thus conceived as 'a process mediated by the collaborative inquiry of individual members' (Aryris and Schon 1978, p.20).

Before we go on to outline the specifics of the model upon which our arguments are based, it is important to note that learning is not always a positive phenomenon, regardless of the level of aggregation at which it takes place. Levitt and March (1988) used the term 'competence traps' to describe situations in which agents adopt patterns of behaviour that appeared to be successful at particular points in time and space, but which have been rendered outmoded. They also used the term 'superstitious learning' to describe situations where a particular decision is followed by a positive but unrelated outcome. Under these circumstances, agents may (wrongly) assume that pursuing similar actions on a related path will lead to further positive outcomes and may use the existence of a (wrongful) causal link to strengthen their positions within an organization and region. This illustrates another facet of learning that will be discussed in more detail in a later section that learning is a political process in which vested interests and resistance to change lead to powerful impediments to learning.

Argyris and Schon assume a tripartite learning process, with each component corresponding to a different method of detecting and correcting perceived errors, and cognitively to a different level of abstraction. Single-loop learning involves detecting and correcting weaknesses in behaviour based on experience (i.e. trial and error); it is a simple 
signal-response model of behaviour well-recognised in the economics literature (see Arthur 1992 and the critique by Clark, Tracey and Lawton Smith 2002). But at this level, agents do not question the assumptions and patterns of behaviour which govern aims and objectives or the procedures designed to obtain them; the purpose of single-loop learning is to achieve existing goals and objectives while ensuring that organizational performance does not move beyond current values and norms. Rules of action and standard operating procedures are often developed so that decisions are made in relation to some agreed reference point. The possibility that the values and operating norms themselves may need to be altered does not form part of the learning process. Examples of single-loop learning might include adjusting levels of output in relation to demand, or improving remuneration in order to improve staff retention.

Where existing values and norms prove sufficient for meeting goals and objectives, and where goals and objectives themselves are sufficient for sustaining firm competitiveness, single-loop learning may be sufficient. In other circumstances, however, where organizational goals and objectives cannot be met within existing frameworks, or where competitive position is lost despite the attainment of a particular set of objectives, agents may be required to question more deep-rooted assumptions which may have been deliberately set aside in relation to more immediate functional objectives. The questioning of such assumptions within firms constitutes double-loop learning. In addition to the detection of error with regard to effective performance in relation to existing goals, doubleloop learning involves the detection of error in relation to the assumptions that underpin effective performance, and the nature of learning itself. Examples of double-loop learning might include seeking ways of redefining existing boundaries between different industries and services so that new niche markets emerge (Morgan 1997), or reconfiguring organization structures to improve the flow of knowledge and information. By reconceptualising problems and restructuring organizational priorities and assumptions double-loop learning can be particularly effective for developing shared understanding within firms and resolving conflict between individuals or organizational sub-units with apparently incommensurate goals.

Triple-loop learning, also known as deutero learning, is a higher order learning process in which agents are able to conceptualise key facets of the modus operandi of their 
learning system, and influence it accordingly, notwithstanding institutional constraints. Thus it is primarily focused on the relationship between firms and the other organizations that constitute their learning system. On an individual basis, agents' capacity to change their learning system is normally limited to the lowest rungs on the 'ladder of aggregation', such as small groups or departments. When agents form networks and alliances, their capacity to influence higher levels of analysis becomes far greater. Triple-loop learning involves the capacity of agents to operate on a higher level of abstraction, and to understand, at least in some general sense, the learning system of which they are part, the kinds of actions needed to engender purposeful change, as well as the limits of such actions. Agents are required to collaborate with other actors in order to reflect on and assess inherited systems of innovation, to consider market situations when innovation was deemed to have been effective, and conversely, when it was deemed to have failed. This allows agents to learn about and to articulate modes of behaviour that facilitate and inhibit learning and innovation, to develop and implement new strategies for innovation, and to evaluate their effectiveness.

In general terms, and despite significant overlap between them, different kinds of knowledge predominate for each level of learning. This is illustrated in Figure 1. Singleloop learning relies mainly on existing or market knowledge that is already in the organizational or regional domain. Error is corrected through established procedures, information or modes of thought, and behaviour remains within fixed boundaries. Doubleloop learning is most closely associated with tacit forms of knowledge. Established patterns of thought and action, and their consequences for performance, are continually considered, questioned and articulated within firms. Solutions are developed which may represent a significant departure from the present but which are rarely at the forefront of market or technological innovation. Triple-loop learning relies mainly upon formal stores of knowledge. The relationship between organizations and their associated institutions that constitute a firm's environment or learning system is conceptualised and articulated formally between and within firms through the use of metaphors and shared frameworks. This allows firms to learn about new ideas and ways of operating, to be proactive with regard to opportunities and threats and thus at least partly shape their competitive circumstances, and ultimately to engage in innovative behaviour. Notwithstanding its 
simplicity, this typology provides a useful conception of the relationship between knowledge and learning.

Although the distinction between double- and triple-loop learning becomes increasingly blurred during innovation (information must flow within as well as between organizations), we believe that triple-loop learning is crucial to innovation, and a defining characteristic of the IKE. If we are correct, the implications for current thinking about economic development are highly significant; the dominant kind of knowledge underpinning innovation in the IKE is not tacit, as is commonly assumed. It is formal and it can be learned. Indeed, Bateson (1972), the anthropologist who first developed the notion of deutero learning, described it as 'learning to learn'. Any conceptualisation of learning systems requires, of course, an understanding of their tacit components - tacit knowledge clearly plays a crucial role in any organizational or regional setting. But it is the ability to understand and articulate tacit knowledge within and between firms, and its interaction with formal knowledge, which underpins innovative behaviour. While this typology is an idealised conception of reality, it is our contention that these processes have become embedded in the institutions and behaviour of knowledge-based regions such as Silicon Valley, and has contributed significantly to the development of the IKE. In the following section, we develop our framework in relation to knowledge-based activity.

\section{Innovation in the IKE}

Storper (1997) provides a useful starting point for considering learning and its relationship to industrial and regional competitiveness. He argues that while 'descriptive monikers' such as post-industrial society, flexible specialization and post-Fordism form valid, if incomplete, theoretical tools for considering economic development, the concept of learning provides the most meaningful logic for understanding sophisticated forms of economic activity capable of sustaining high wages and living standards. This is because although esoteric knowledge presents significant challenges for competitors seeking to copy and exploit it, competitive advantage in general, and knowledge in particular, is continually subject to 'powerful forces of standardization and imitation' (p.265) which will inevitably result in their substitution and/or relocation. This necessitates a sustained process of learning and innovation in which products and processes are continuously 
updated and improved so that competitiveness can be maintained. For this to happen, agents must go beyond the cycle of single-loop learning that pervades much of human behaviour, and engage in double- and triple-loop learning.

In order to understand the learning process it is not sufficient to look only at what agents learn. It is also necessary to examine the ways in which knowledge is acquired, shared and evaluated in the setting in which their behaviour takes place. Innovation is strongly influenced by social and institutional factors; firms and regions have their own ways of communicating and legitimising knowledge. In other words, agents' interpretations of their experiences and the meanings they attach to knowledge and learning varies between institutional and geographical contexts. In this respect, the role of institutions at all levels of aggregation is crucial.

Community networks and relational capital have long been regarded as fundamental to innovation systems. Porter $(1998,2000)$, probably the most influential exponent of the virtues of spatial clustering, described clusters as interconnected companies and related institutions, the relationship between which is characterized by a complex mixture of competition and cooperation. Typically, clusters have vertical (customers and suppliers) and horizontal (producers of complementary products and specialist infrastructure) dimensions. Depending upon their sophistication, they might include other public and private institutions that provide specialized training, information and technical support, as well as trade associations and regulatory agencies. These actors are bound together by networks of social relationships with their own conventions and modes of expected behaviour that encourage open communication and the sharing of knowledge and information. Porter argues that clusters enhance competitiveness in a number of ways: (1) by facilitating access to specialized labour markets and superior or lower cost inputs such as components, machinery and business services; (2) by facilitating access to market, technical and other specialized knowledge and information, both explicit and tacit, which allows related firms to more easily perceive the need and opportunity for innovation; (3) by encouraging the development of complementary products and services; (4) by facilitating low-cost access to benefits such as specialized infrastructure, and advice from experts in local institutions; while (5) encouraging comparison and performance measurement in relation to local rivals. 
These arguments have been articulated in more sophisticated ways by scholars such as Antonelli (2001) and Asheim (1996, 2000), and provide important insights for understanding the IKE in particular and regional development in general. Such accounts are, however, incomplete. As Malmberg and Maskell (2001) pointed out, existing theoretical analyses of spatial clustering do not explain why constituent firms are able to engage in innovative behaviour in ways that larger firms or clusters in other regions are apparently unable to replicate. In particular, they argue that much current thinking fails to articulate the processes through which competitiveness is enhanced (the sharing of knowledge and the transfer of technology), focusing instead on 'hypothetical local spillovers', the evidence for which is the existence of the clusters themselves. The result is a 'circular causation' which fails to articulate adequately the processes involved. We would further suggest that the existence of open communication channels and the resultant sharing of knowledge and information cannot per se account for sustained innovation over long periods given the rapidly changing market environments in which firms operate, and the powerful defensive routines (discussed below) which tend to bind agents to current patterns of thought and action. We address this lacuna by offering a prototypical framework of learning which seeks to describe and explain the complex interactions between the cognitive, institutional and organizational factors that account for the innovative behaviour that characterizes the IKE. Our framework consists of three propositions and constitutes an 'ideal type' which does not refer to specific regions or industries located in time and space. This is left to the subsequent section.

$P_{1}$ : The key to learning lies in the articulation or formalization of tacit knowledge and its relationship to explicit knowledge. ${ }^{3}$ Argyris and Schon (1978) use the term 'theory-in-use' to describe the pictures or representations that agents build of their learning systems. Such pictures are always incomplete. Part of the learning process involves agents' endeavour to complete the picture, to conceptualise their place in relation to other actors, and to account for their actions by constructing and maintaining their social interactions. 'They [agents] try to describe themselves and their own performance insofar as they interact with others.

\footnotetext{
${ }^{3}$ This point is also made by Nonaka and Takeuchi (1995).
} 
As conditions change, they test and modify that description. Moreover, others are continually engaged in similar enquiry. It is this continual, concerted meshing of individual images of self and others, of one's own activity in the context of collective interaction, which constitutes an organization's knowledge of its theory-in-use' (p.16).

In order to learn and change, individuals must continually question and examine existing norms and assumptions which constitute their 'theory in use', both informal and explicit, and the relationship between them, in response to new information, circumstances and insights. Reflexivity, by which we mean the continual framing and reframing of assumptions and norms, is the cornerstone of intelligent behaviour. Interaction and communication with other organizations and their members is a crucial component of this process because it exposes agents to new ways of working and thinking. Dialogue encourages agents to question their belief systems and to construct shared representations of the roles of different organizations and institutions at different levels of aggregation, thereby improving their understanding of their learning systems. Language allows for such interaction to take place by providing categories for agents to define their worlds and describe their experiences. However, given the socially embedded nature of meaning, it can also reinforce current patterns of thought and action because language is central to agents' beliefs, values and structures.

For these "local traps" to be overcome, and in order to understand the diverging interpretations, aims and objectives held by the parties involved, agents must conceptualise and articulate their experiences through the use of shared metaphors, analogies, templates, mental models, concepts and frameworks. They must question how they see and think about their learning system and how its different components interact. Individuals are able to transpose what they have learned to higher levels of aggregation, both within and between firms, such as teams, departments or whole organizations through the creation of these shared systems of meaning. This is because social roles and institutions are sustained by the meaning and significance that agents attach to them, and their existence depends on their confirmation and reconfirmation by agents. We agree with Silverman (1970) that 'we reify society if we regard it as having an existence which is separate from and above the actions of men [sic]' (p.134). 
Figure 2 demonstrates our conception of the relationship between levels of learning and firm responses to changing circumstances. Firms that engage primarily in single-loop learning tend to be reactive; they allow themselves to be shaped by market and other forces and are slow to make the kind of internal adjustments necessary to reposition themselves in dynamic environments. In industries where the rate of change is particularly fast, singleloop behaviour is unlikely to be sufficient to maintain competitiveness. Firms that engage primarily in double-loop learning are always looking for new and better modes of operating, and can be characterised as exploitative or adaptive. Intra-firm patterns of behaviour are continually questioned and altered so that agents are able to take advantage of new opportunities that emerge. These firms are usually able to sustain competitiveness, but tend to be one step behind the leading firms. They are well placed to adjust to changing circumstances, but rarely influence them. By contrast, firms that engage primarily in triple-loop learning can be described as proactive. These are the firms that shape markets and products through new product development and new market entry. They understand the learning system of which they are part and use their ability to collaborate and develop shared meaning with other actors to define the boundaries for others.

$P_{2}$ : The IKE exists within an institutional configuration that encourages double- and triple-loop learning. Institutions have a powerful influence on learning and decisionmaking: their purpose is to guide action and convey expected behaviour, particularly during periods of uncertainty. Thus we can say that they have a coordinating function. In this context, we can also say that some institutional environments are more conducive to successful economic activity than others, and that the competitiveness of firms, regions and nations is profoundly affected by their inherited institutions. As implied by our first proposition, however, institutions do not form fixed boundaries for behaviour and economic activity. Agents may select, adapt or ignore aspects of their inheritance, even if inherited economic resources and knowledge and information about prospective opportunities affect their capacity to do so (Clark, Tracey and Lawton Smith 2002). In the context of the IKE, double- and triple-loop learning processes constitute a form of relational capital. Community networks of interaction that encourage trust, the sharing of 
knowledge and information, and the questioning and reframing of norms and assumptions may be viewed as institutions to be reproduced from one period to the next given their contribution to long-term collective competitiveness. In some circumstances, therefore, these kinds of inherited institutional configurations may reinforce existing virtuous patterns of growth, as firms can use their strong inherited resources (locations) to more easily generate the conditions for their future success. It may seem like a paradox, but we are essentially arguing that the continual questioning of the social and institutional influences which constitute agents' learning systems itself becomes institutionalized in the IKE, and is reinforced and confirmed through the actions of agents. This has enabled double- and triple-loop learning to become internalised and socially embedded, thereby reinforcing innovative behaviour in a cumulative manner.

Unlike institution-centred approaches to economic development, our agent-centred model does not assume that institutions necessarily overwhelm cognitive capacity or bypass consciousness through the 'tacitness' of the information they convey. We view institutions as much more that merely shared schemas for regulating behaviour and disseminating information: they are mechanisms which are at least partly created, manipulated, refined and often discarded in order to facilitate learning and innovation. Pragmatically, of course, we accept that the extent to which social institutions can be altered, or reframed, is extremely varied; some modes of relational capital are so deeprooted that meaningful change is exceptionally problematic. Nevertheless, we clearly prioritise cognition and meaning over institutions, rather than vice versa. ${ }^{4}$

In figure 3 we illustrate the relationship between learning and institutional inheritance. Regions that are characterised mainly by single-loop learning tend to be poorly endowed with social and institutional capital. While it is possible for firms to engage in higher levels of learning in such circumstances, this is very much the exception rather than the norm. In particular, high levels of uncertainty and low levels of trust characterise relationships between firms, which tend to operate autonomously. Regions

\footnotetext{
${ }^{4}$ Antonelli (2000) points out that systems of learning and innovation are 'themselves the - partly intentional outcome of long-term routines, codes of conduct, and actual investments implemented by the strategic behavior of agents and governments to increase the innovation capabilities of economic systems... effective connections are the result of deliberate action and should be considered endogenous: an effort has to be made to establish each effective connection' (p.404). In this paper we have sought to introduce a cognitive dimension to this process, and to articulate what is distinctive about the patterns of thought and action that characterize innovative behaviour in the IKE.
} 
characterised mainly by double-loop learning can exist in environments that are institutionally impoverished, neutral or rich, because double-loop learning is concerned for the most part with internal adjustments and patterns of behaviour. However, it is quite unusual for regions characterised mainly by triple-loop learning to exist in institutionally impoverished environments, because triple-loop learning requires collaboration with other actors that understand the kinds of behaviour necessary for innovation. Relationships between firms are characterised by systems of shared meaning and expectations, and by a high degree of reciprocity.

$P_{3}$ : Patterns of organization encourage the sharing of knowledge and information within and between firms. Double and triple-loop learning takes place simultaneously within as well as between firms, with agents and their firms continuously making adjustments in relation to what they have learned from interaction with other actors, as their understanding of their learning system evolves and/or improves, and as agents reinterpret their circumstances and behaviour in order to develop and articulate new and better contexts for learning. In order to correct error or develop new contexts for learning, however, organizations and the production systems of which they are part tend to assume particular structures, cultures and patterns of organization which manifest themselves explicitly in formal procedures and implicitly through routines and modes of thought.

Hierarchical and horizontal divisions within and between firms create barriers to the flow of knowledge and information. The result is sub-units that interpret common problems from different reference points. This encourages the creation of political boundaries that further inhibit learning and innovation. Considered organizationally, innovative firms tend to be characterized by limited hierarchy and levels of autonomy that empower individuals and teams (Teece 2000, p.57-58). Notions of rank, seniority and functional specialization are deemed to inhibit the flow of information and ideas, and as mechanisms that destroy unity and a shared sense of purpose. Thus decisions are taken in ways that are simple and informal, with open and responsive systems of communication and coordination between different parts of the organization. Teece further suggests that innovation requires '[social] institutions with relatively low-powered incentives, where information can be freely shared without worry of expropriation, where identities can 
commit themselves and not be exploited by that commitment, and where disputes can be monitored and resolved in a timely way' (p.65). Similarly, Morgan (1997) argued for the importance of autonomy and decentralization of power and decision making: 'even though goals, objectives and targets may be helpful managerial tools, they must be used in a way that avoids the pathologies of single-loop learning; goal seeking must be accompanied by an awareness of the "limits" needed to avoid noxious outcomes; and hierarchy, design and strategic development must be approached and understood as self-organizing, emergent phenomena' (p.117).

These firms challenge traditional premises about effective management, including strong leadership, central control, the development of clear aims and objectives, and the role of hierarchy. Such assumptions, which manifest themselves in the form of, for example, management control systems and standard operating procedures to monitor measures of performance such as sales, profit and productivity, tend to reinforce singleloop learning processes because they are designed to ensure that firms remain within predetermined boundaries. The increased use of management information systems and other IT-based monitoring systems has augmented this pattern (Morgan 1997). Argyris and Schon (1996) argued that these structures encourage agents to engage in defensive routines, 'actions and policies that are intended to protect individuals from experiencing embarrassment or threat, or the organization as a whole from identifying the causes of the embarrassment or threat in order to correct the relevant problems' (p.99-100). At the level of the firm, defensive routines can become embedded in formal and informal structures, norms and ways of thinking and acting.

In figure 4 we have summarised the forms of industrial organization generally associated with different levels of learning. Firms engaged in single-loop learning tend to be organised bureaucratically. Although power and responsibility may be diffused rather than centralised, this form of organization emphasises the importance of formal and clearly defined roles and operating procedures at the expense of individual judgement. The aim is to encourage behaviour which is predictable, consistent and within current parameters. Hierarchical and functional divisions form significant barriers to the flow of information within these firms, and their relationships with external organizations tend to be rudimentary. Often, sub-cultures develop within organizations that encourage the kinds of 
defensive routines discussed above. By way of contrast, firms engaged in double-loop learning are organised organically. Decisions are based on expertise and persuasion rather than on formal roles and standard operating procedures. Where conflict arises it is resolved through formal and informal dialogue between the actors concerned, rather than through 'superiors' who occupy more senior positions. Dialogue also serves a coordinating function by allowing knowledge and information to flow throughout organizations, thereby allowing the priorities and objectives of sub-units to be understood and accommodated. Double-loop learning firms tend not, however, to be engaged in complex relationships with other actors, and so knowledge and information flows mainly within firms rather than between them.

Firms engaged in triple-loop learning tend to participate in sophisticated networks with related organizations that allow them to shape competitive circumstances and to learn new ways of operating. These firms are generally organized organically between as well as within firms. This is particularly the case for firms that develop innovative products and processes that are not compatible with existing technological and market structures. Teece (2000) calls this 'systemic innovation' and gives the examples of film-based instant photography (that required the redesign of the camera and the film), and the compact disc (which required the redesign of audio equipment and the cooperation of the music industry). It is most unlikely that a single firm could significantly reconfigure and commercialise an entire system, and so firms are required to form well-coordinated tripleloop relationships with other organizations that have complementary capabilities and capacities. In these circumstances, clear but informal channels of communication and high levels of trust are required so that knowledge and information flows as freely between firms as it does within them. This is complicated by the fact that networks may contain firms of varying sizes, resources and power, and because agents in different organizations may not interpret circumstances consistently.

\section{Implications for European Regional Development}

We are now in a position to consider the role and status of the IKE in Europe. In figure 5 we have conceptualised the relationship between levels of learning and European regional development. European regions designated Objective One by the European Commission 
are likely to be characterised by single-loop learning. They tend to be heavily dependent on labour intensive industries that are subject to considerable low-cost competition from the developing world. Strategies to improve competitiveness tend to focus predominantly on lowering labour and other operating costs and improving productivity. Firms may seek to exploit new markets, but are unlikely to engage in significant new product development or innovation. Examples might include Thessaly and Central Macedonia in Greece, and much of Southern Italy.

We have labelled double-loop learning regions as transition regions. Economic activity is likely to consist of a mix of labour-intensive and more sophisticated knowledgebased industries. In both cases, firms compete mainly in niche markets where the valueadded is higher and where price-based competition is less intense. Firms are continually seeking new markets and opportunities and tend to invest heavily in training, technology and product development in order to improve their competitiveness. Their structures and modes of operating allow them to adjust quickly to changing circumstances and to adopt new ideas, but they are rarely at the vanguard of technological development. Examples might include 'Silicon Glen' in the UK and the 'Third Italy'.

Regions engaged mainly in triple-loop learning are characterised by high levels of knowledge-intensive firms that tend to be at the forefront of technological and market innovation. These are the firms that shape products and markets rather than simply respond to opportunities and threats that emerge. They develop sophisticated networks of related firms that share knowledge, ideas and resources, and allow for the development of distinctive technological systems that represent a significant break from the past. The sharing of information and knowledge about products and processes creates new and idiosyncratic forms of competitive advantage. While these networks are focused locally, firms search globally for opportunities and resources. In particular, they tend to outsource those activities that can be performed more quickly and/or more efficiently by others. Examples might include Baden-Württemberg in Germany and Cambridgeshire and Oxfordshire in the UK.

At issue here is how best to encourage European firms and regions to engage in knowledge-based activity and its associated modes of learning in order to improve competitiveness and wealth creation. Europe's social and economic institutions are 
characterised both by great diversity between countries and by a level of persistence at odds with corresponding US structures. Despite the apparent increasing diffusion of Anglo-American capitalism throughout continental Europe, the differences between the US and the economies of Europe remain profound. In particular, and unlike the US where the logic of profit maximization is deeply embedded, greater emphasis is placed on the social dimensions of economic activity in continental European. Attempts to reconfigure aspects of Europe's economic system must take account of such differences. To apply AngloAmerican modes of knowledge governance to a European context is in the first instance untenable because of the incompatible and deeply entrenched nature of existing European institutional arrangements, and in the second instance constitutes a form of intellectual imperialism which may not be acceptable to the inhabitants of Europe, many of whom remain sceptical of the 'superiority' of the US system.

We must accept, then, that European policy makers seeking to encourage knowledge-based activity operate within a set of institutional constraints, particularly with regard to the structure and performance of capital and labour markets. It is extremely unlikely that the system of labour market flexibility and venture capital that characterises the IKE in successful US regions will emerge in continental Europe for the foreseeable future. These mechanisms are not, however, prerequisites for the IKE. Pockets of knowledge-based activity have emerged in a small number of European locations, such as Baden-Württemberg and Switzerland, albeit on relatively a modest scale by US standards.

Given the peculiarities of European capital and labour markets and our argument that the most important facet of knowledge-based activity is double- and triple-loop learning, care must be taken in assessing the growth prospects and logic of the IKE. The key issue here is the extent to which proximity and local networks are necessary for learning and innovation. Is there any reason to suppose that so-called 'untraded interdependencies' such as co-operative behaviour between agents, and a culture of shared expectations and meaning cannot exist between agents located in different jurisdictions? It may be true, as Maskell et. al. (1998) have argued, that trust and the articulation, formalization and ultimately the transfer of tacit knowledge is more straightforward through face-to-face interaction between agents with a shared cultural heritage, and where local technological infrastructures encourage knowledge spillovers into the local economic 
system. We suspect, however, that such an approach again exaggerates the importance of tacit knowledge and geography in relation to formal knowledge, and underplays the role of cognition and agents' capacity to understand the social world of which they are part. Further, and as Amin (2000) points out, to assume competitiveness lies mainly within local or even national production systems is to ignore evidence which indicates the prominent role of spatially elongated networks and hierarchies which cut across national boundaries. (See, for example, Dunning 1997).

Knowledge-based activity is increasingly decentralised, being re-formed into partly competing, partly complementary nodes situated in different locations around the world (see Castells 1996; McKendrick, Doner, and Haggard 2000). The accelerated development of advanced transportation and communication technologies has enabled firms to coordinate more effectively their international activities. Also, the deregulation of markets and the liberalisation of trade more generally have led to an increasing number of potentially attractive investment locations. Centrifugal forces, such as the need to reduce labour and other operating costs, the need to access new markets, and the possibility of other location specific advantages such as specialist labour markets, have further encouraged IKE production units to disperse their activities across several locations.

We agree with Amin (2000) who argues that that the development of these transnational linkages has led to new corporate geographies being superimposed upon existing ones. This does not deny the central role of indigenous production units and local social capital: the most successful industrial clusters are characterised by large numbers of local production units that rely (formally or informally) upon one-another and develop into larger ones. We simply argue that knowledge-based activity is increasingly an international and decentralized activity rather than only a regional phenomenon. In any case, participation in international networks usually precipitates the emergence of new and distinctive practices and modes of operation, rather than the replacement of existing institutional arrangements by models of 'best practice' imported from other places. This is entirely consistent with our views, outlined in a previous paper (Clark, Tracey and Lawton Smith 2001), that the interpretation of common concepts varies between locations. Agents often use bridging mechanisms, such as the common imperatives that underpin capitalism, to promote mutual understanding. But ideas and practices imported from other 
jurisdictions are necessarily transmutated through existing institutional structures and interpretive lenses, which are themselves modified during this process. This is what underpins social change and ensures the persistence of diversity between systems of accumulation, despite the relatively open transfer of knowledge and information between places.

This has significant implications for European regional development: 'mere' imitation or blindly copying the practices of so-called exemplar regions will ensure that European levels of competitiveness remain below those of its currently more successful rivals, such as the US, for the foreseeable future. Only by learning about the virtues of other systems and marrying these to Europe's existing strengths, can it hope to leapfrog the US and establish itself as a model for others. In this context, double- and triple-loop learning provides a powerful reference point with which to view innovation and economic development. We suggest that the growth of the IKE in Europe could be linked in part to external forces, with multinational corporations, which have been instrumental in the growth of industrial districts around the world, playing a crucial part. In the previous section we outlined three propositions in relation to successful knowledge-based activity. In the remainder of this section we look at these in turn in the context of European regional development.

$P_{1}$ : The key to learning lies in the articulation or formalization of tacit knowledge and its relationship to explicit knowledge. This is a process that needs to be carried out within and between organizations, and European firms need to be more proactive in this respect. Agents at all levels must learn to appreciate the complexity and diversity of the issues they face, and to recognise, absorb and manage this complexity. To understand and articulate tacit knowledge, individuals, teams, and other units must be 'empowered to find innovations around local issues and problems that resonate with their needs. This also provides a resource for innovation within the broader organization, as the variety and innovation thus experienced is shared and used as a resource for further learning' (Morgan 1997, p.113). We envisage a shared decision-making process where agents transfer information, insights and ideas, and where consensus and shared meaning emerges from interaction, rather than being imposed by hierarchies with vested interests in maintaining 
the status quo. Decisions, and the values and norms that underpin them, need to be explored from multiple perspectives so that courses of action that satisfy multiple perspectives and concerns can be developed.

This takes us back to the crux of our argument about human behaviour: while agents are, at one level, social beings moulded in thought and action by their environments, they have the capacity to operate at a higher level of abstraction, to make judgements about how the different parts of their learning system fit together, to take action to engender meaningful change, and to make judgements about the limits of such action. In other words, agents in European firms need to learn to learn.

$P_{2}$ : The IKE exists within an institutional configuration that encourages double- and triple-loop learning. Management theory has traditionally stressed the importance of organizational design and structure for sustaining and improving competitiveness. Our model envisages an alternative source of competitive advantage: language, values, social interaction and the exchange of ideas. As noted above, European firms are faced with the challenge of developing systems of shared meaning, encouraging their members to question the current parameters within which their behaviour is evaluated by others, and developing strategies for action that take into account the structure and limits of the learning system of which they are part.

For this to happen in a sustained fashion, new kinds of thinking need to become transposed onto the structures and modes of operation of organizations and other institutions which constitute their environments. We see this partly as a challenge of cultural change: the introduction of new forms of technology, organization and operating procedures are necessary but insufficient for the emergence of distinctive patterns of learning. We recognise, of course, that cultural change is highly problematic: 'Corporate culture rests in distinctive capacities and incapacities that are built into the attitudes and approaches of organizational members. Culture is not something that can be measured on a scale because it is a form of lived experience. Managers can influence that experience by being aware of symbolic consequences of their actions and by attempting to foster desired values. But they can never control culture in the way that many management writers advocate' (Morgan 1997, p.152). 
But unless we can suggest ways of introducing double- and triple-loop learning into the European context, we cannot move beyond the circular arguments of which we were critical earlier in this paper. We consider the participation of European firms in spatiallyelongated networks of knowledge-based activity to be crucial, because this will expose agents in European jurisdictions to new modes of thinking and acting. These networks are presently located mainly in the US. However, our model of institutional change allows for the introduction of new ideas and modes of thought which are compatible with existing structures. These ideas will take new and unpredictable forms that may allow European firms and regions to move beyond existing models of best practice. This should generate a momentum which is self-reinforcing: the presence of even small numbers of internationally competitive firms in a given region or production system can contribute significantly to the competitiveness of other firms by acting as role models and sources of ideas for them.

$P_{3}:$ Patterns of organization encourage the sharing of knowledge and information within and between firms. Few aspects of the American capitalist model have been so influential as the bureaucratic, hierarchical and vertically integrated form of industrial organization. The application of scientific management (the separation of management's thought from labour's doing) and the development of the multidivisional form of organization was seen by Alfred Chandler and his acolytes as the cornerstone of American economic hegemony in the period following the Second World War. While many European countries were slow to adopt these practices and their associated ideas, there can be little doubt that they have been very influential in the post-war development of European industrial and economic structures, and economic development more generally. It is surely ironic that the flexible specialization advocated by Piore and Sabel (1984), a form of which now permeates the IKE in the US, was widespread in parts of Europe prior to 1945, but was at least partly rejected in favour of horizontally and vertically integrated corporations which were influenced by 'scientific' approaches to management because of the apparent superiority of the US system. (See McKinley and Zeitlin 1986 and Ackroyd and Lawrenson 1996 for the case of the UK). 
We noted earlier that we believe the creation of new forms of management and organization is in many respects a challenge of cultural change. It involves creating systems of meaning that are shared by agents at all levels and who accept, internalise and act upon them. Thus innovation requires that organizations have a 'holographic' quality (Morgan 1997), with the attributes of the whole transposed onto its constituent parts. This involves a particular form of organization: 'The best teams, and the free-flowing organizations that have discarded bureaucratic forms of management, constantly reflect this quality. They are organised through core meanings that people own and share. It is this quality that allows them to be flexible, adaptive and non-bureaucratic. Organizationally, shared meanings provide alternatives to control through external procedures and rules' (p.143). Although the advantages of democratic forms of organization are well known, particularly for firms operating in turbulent environments, the extent to which such forms are widespread is less clear. Without open channels of communication and flat hierarchies that allow agents to share their experiences within and between organizations, it is difficult to envisage how the first two propositions can be achieved.

\section{Conclusion}

At the Lisbon summit, European leaders and EU officials recognised that continental European economies were slipping behind their Anglo-American counterparts. Regardless of which measure of performance is used it seems apparent that Anglo-American economies and in particular the United States is on a different and higher long-term growth trajectory. This has prompted considerable debate about the slowness of European economic integration, and the need for reforms of nation-state and EU institutions in ways consistent with the perceived requirements of the information and knowledge economy. Indeed, there is a widespread perception that the European growth prospects are bound up with the extent to which the institutions and practices of the IKE can be adopted and

flourish in Europe. Essential to this model of economic growth, it appears, are geographical clusters of innovation as exemplified by Silicon Valley and Route 128 Boston. 
In this paper, we have argued that conventional explanations of the information economy often fall short. Most obviously, there is a temptation to ascribe causal significance to the clustering of activities in certain regions supposing that an essential prerequisite for building a knowledge economy is the existence of such clusters; there remains an unresolved question of whether clustering is a cause or an effect of the information economy. Also important, however, is the realisation that common understandings in the regional development literature about the nature of learning (the translation of information into knowledge) are at best rudimentary and at worst rather unsophisticated in the light of parallel debates in the management sciences concerning the modes and mechanisms of learning and knowledge acquisition. In this paper, one goal has been to articulate a more complete model of learning and knowledge acquisition relying upon models of cognition and search that can be attributed, in part, to the early work of Simon and Aygris and Schon. From these models, we have advanced (we hope) a more nuanced account about the possible implications of the knowledge economy for European regional development.

In making our assessment, we have been guided by two rather basic suppositions drawn from our knowledge of contemporary Anglo-American and European circumstances. In the first instance, we are very conscious of the fact that a Europe is a very different economic environment than its Anglo-American brothers and sisters. The commonplace expectations about capital market and labour market flexibility that are so important to the Anglo-American world are rarely matched in European nations and regions. Europe is dominated by that which was inherited from the immediate post-war settlement, and various competing conceptions about the nature and significance of culture, society, and the proper relationship between economy and civil society. In the second instance, we are also very conscious of the fact that Silicon Valley and similar kinds of regional systems of innovation exist - to imagine that the proper response is to build competing clusters of innovation in continental Europe seems at best a long-term prospect and at worst a forlorn hope. We should, however, look for ways that European industry might take advantage of the existence of Silicon Valley to build institutions and encourage entrepreneurship that is able to systematically leapfrog Anglo-American initiatives. 
In other words, we are less convinced that the knowledge economy is essentially a geographical phenomenon than we are convinced that the knowledge economy is a distinctive form of learning utilising intellectual capital in mutually reinforcing institutional environments. Of course, we appreciate the fact that these kinds of environments may be local in ways consistent with Marshallian industrial districts of the 19th century and regions such as the third Italy of the 20th century. But we would also contend that if Europe is to leapfrog the Anglo-American world in terms of its innovative potential it cannot wait for a new Silicon Valley in Europe. Surely the immediate future must be the formation of learning environments that bring together in virtual spaces the intellectual potential of European industry. The contrast we wish to draw here is between localised centres of innovation and spatially elongated centres of innovation that rely upon advanced communication technologies and moments of interaction that achieve the same result: "centres" of innovation that spin-out ideas into the market place thereby contributing to the long-term growth of capital accumulation and labour productivity (contra Saxenian 1994).

Our analysis of the learning process drew distinctions between simple and more complex conceptions of reflexivity. So much of the literature is preoccupied with what is termed single-loop learning (signal-response) or possibly double-loop learning (response and adjustment) that analysts often miss the importance of so-called triple-loop learning (learning to learn). At the same time, many analysts tend to treat institutions and regions as entities that can learn ignoring the fact that it is individual agents who are the locus of cognitive capacity. We do not dispute the significance of institutions and regions for the learning process; in the best of worlds, these entities are extremely valuable resources for facilitating and economising upon the learning process. They embody all kinds of useful heuristics and templates that allow for the translation of decisions into actions. But equally institutions and regions can be impossible burdens upon agents' imagination and innovation (see Clark, Tracey, and Lawton Smith 2002). The interaction between agents and their environments determines the growth potential of the information economy.

But we must be cautious about their interaction. Agents are more than their environments. They learn, they develop mechanisms for learning, and they often fail to recognise their own mistaken choices and those of their colleagues. Agents need not 
benefit from their environments nor necessarily contribute to the growth potential of their environments. Indeed, many institutional and regional circumstances, whether AngloAmerican or European, seem irrelevant to the growth potential of their citizens. Too many environments are resource-poor, are paralysed by political consensus seeking, and are merely instruments of government policy. We have many examples of these cases but, unfortunately, we have few instances of so-called successful regions. Silicon Valley and Rt 128 Boston and other similar places have become emblems or symbols of success rather than real examples of the scope of potential interaction between learning and the knowledge economy. More important than regions, we would argue, is a better understanding of cognitive capacity, decision-making, and how and why knowledge is so essential to the IKE.

In this respect, we argue for a shift in focus from tacit knowledge (the presumed engine of innovation) to the ways in which knowledge is formalised, revised and adapted to changing circumstances. We argue that tacit knowledge cannot be the source of innovation. And we argue that tacit knowledge is always incremental rather than developmental. Organising systems of triple-loop learning are essential to the growth of the information economy in Europe and elsewhere. We do not under-estimate the difficulty of this kind of institution-building. But we are convinced that institutions or regions by themselves are neither necessary nor sufficient for the process of innovation. By contrast managing cognition, building ready mechanisms of response and change are necessary conditions for the IKE. 
Figure 1. Levels of learning and types of knowledge

\begin{tabular}{|l|c|c|c|}
\hline & Single & Double & Triple \\
\hline Market & $\mathbf{X}$ & & \\
\hline Tacit & & $\mathbf{X}$ & \\
\hline Formal & & & $\mathbf{X}$ \\
\hline
\end{tabular}

Figure 2. Levels of learning and response to changing circumstances

\begin{tabular}{|l|c|c|c|}
\hline & Single & Double & Triple \\
\hline Reactive & $\mathbf{X}$ & & \\
\hline $\begin{array}{l}\text { Exploitative/ } \\
\text { Adaptive }\end{array}$ & & $\mathbf{X}$ & \\
\hline Proactive & & & $\mathbf{X}$ \\
\hline
\end{tabular}


Figure 3. Levels of learning in the context of institutional inheritance

\begin{tabular}{|c|c|c|c|}
\hline -ve & Single & Double & Triple \\
\hline$\sim$ & $\mathbf{X}$ & $\mathbf{X}$ & \\
+ve & & $\mathbf{X}$ & $\mathbf{X}$ \\
\hline
\end{tabular}

Figure 4. Levels of learning and industrial organization

\begin{tabular}{|l|c|c|c|}
\hline & Single & Double & Triple \\
\hline Bureaucratic & $\mathbf{X}$ & & \\
\hline $\begin{array}{l}\text { Organic within } \\
\text { firms }\end{array}$ & & $\mathbf{X}$ & \\
\hline $\begin{array}{l}\text { Organic within } \\
\text { \& between firms }\end{array}$ & & & $\mathbf{X}$ \\
\hline
\end{tabular}


Figure 5. Levels of learning in the context of European regional development

\begin{tabular}{|l|c|c|c|}
\hline $\begin{array}{l}\text { Objective One } \\
\text { regions }\end{array}$ & $\begin{array}{c}\text { Single } \\
\text { - Southern Italy } \\
\text { - Thessaly }\end{array}$ & Double & Triple \\
\hline $\begin{array}{l}\text { Transition } \\
\text { regions }\end{array}$ & & $\begin{array}{c}\text { - Third Italy } \\
\text { - Silicon Glen }\end{array}$ & \\
\hline $\begin{array}{l}\text { Knowledge- } \\
\text { intensive regions }\end{array}$ & & & $\begin{array}{c}\text { - Baden-Württemberg } \\
\text { - Cambridgeshire }\end{array}$ \\
\hline
\end{tabular}




\section{References}

Ackroyd, S., I. Glover, W. Currie and S. Bull. 2001. The triumph of hierarchies over markets: information systems specialists in the current context. In Professions at Bay: Control and Encouragement of Ingenuity in British Management edited by I. Glover and M. Hughes. Aldershot: Ashgate.

Ackroyd, S. and D. Lawrenson 1996. Manufacturing decline and the division of labour in Britain. In The Professional-Managerial Class: Contemporary British Management in the Pursuer Mode edited by I. Glover and M. Hughes. Aldershot: Avebury.

Amin, A. 2000. The EU as more than a triad market for national economic spaces. In The Oxford Handbook of Economic Geography edited by G.L. Clark, M.P. Feldman, M.S. Gertler. Oxford: Oxford University Press.

Antonelli, C. 2000. Restructuring and innovation in long-term regional change. In The Oxford Handbook of Economic Geography edited by G.L. Clark, M.P. Feldman, M.S. Gertler. Oxford: Oxford University Press.

Antonelli, C. 2001. The Microeconomics of Technological Systems. Oxford: Oxford University Press.

Argyris, C. and D.A. Schön. 1978. Organizational Learning: A Theory of Action Perspective. Reading, MA: Addison-Wesley.

Argyris, C. and D.A. Schön. 1996. Organizational Learning II: Theory, Method and Practice. Reading, MA: Addison-Wesley.

Arthur, W.B. 1992. Increasing Returns and Path Dependence in the Economy. Ann Arbor: University of Michigan Press.

Asheim, B.T. 1996. Industrial districts as 'learning regions': a condition for prosperity? European Planning Studies 4, 379-400.

Asheim, B.T. 2000. Industrial districts: the contributions of Marshall and beyond. In The Oxford Handbook of Economic Geography edited by G.L. Clark, M.P. Feldman and M.S. Gertler. Oxford: Oxford University Press.

Bateson, G. 1972. Steps to an Ecology of Mind. San Francisco: Chandler Publishing Company.

Blackler, F. 1995. Knowledge work and organization: an overview and interpretation. Organization Studies, 16, 1021-46.

Castells, M. and P. Hall. 1994. Technopoles of the World: The Makings of $21^{\text {st }}$ Century Industrial Complexes. London: Routledge. 
Castells, M. 1996. The Rise of the Network Society. Malden, MA: Blackwell.

Clark, G.L and J.C. Marshall. 2002. Decision-making: models of the real-world and expertise. Paper presented at the National Association of Pension Funds Conference, Edinburgh, March 2002.

Clark, G.L., P. Tracey and H. Lawton Smith. 2001. Rethinking comparative studies: an agent-centred perspective. Paper presented at the Association of American Geographers Annual Conference, New York, February/March 2001.

Clark, G.L., P. Tracey and H. Lawton Smith. 2002. Agents, endowments and path dependence: a model of multi-jurisdictional regional development. Geographische Zeitschrift. (Forthcoming).

Cooke, P. and K. Morgan. 1997. The Associational Economy: Firms, Regions and Innovation. Oxford: Oxford University Press.

Deal, T.E. and A. Kennedy. 1982. Corporate Culture. Reading, MA: Addison-Wesley.

Dosi, G. 1988. Institutions and markets in a dynamic world. The Manchester School 56, $119-46$.

Dunning, J. 1997. Alliance Capitalism and Global Business. London: Routledge.

Gigerenzer, G. 2001. The adaptive toolbox. In Bounded Rationality: The Adaptive Toolbox. Edited by G. Gigerenzer and R. Selten. Cambridge, MA: MIT Press.

Gigerenzer, G. and P. Todd. 1999. Simple Heuristics that Make Us Smart. Oxford: Oxford University Press.

Grabher, G. 1993. (Ed.) The Embedded Firm: On the Socio-economics of Industrial Networks. London: Routledge.

Hasselbadh, H. and J. Kallinikos. 2000. The project of rationalization: a critique and reappraisal of neo-institutionalism in organization studies. Organization Studies 21, 4, 697 720.

Hodgson, G.M. 1996. Institutional economics. In International Encyclopedia of Business and Management. Edited by M. Warner. London: Routledge, 2174-2189.

Kaufman, A. and F. Todtling. 2000. Systems of innovation in transitional industrial regions: the case of Styria in a comparative perspective. Regional Studies 34, 29-40.

Lave, J. 1988. Cognition in Practice: Mind Mathematics and Culture in Everyday Life. Cambridge: Cambridge University Press. 
Lawton Smith, H. 2001. Innovation support in Oxfordshire. In Promoting Local Growth: Process, Practice and Policy edited by M. Taylor and D. Felsenstein. Aldershot: Ashgate.

Levitt, B., and J. G. March. 1988. Organizational Learning. Annual Review of Sociology $14,319-40$.

McKendrick, D.G., R.F. Doner and S. Haggard. 2000. From Silicon Valley to Singapore: Location and Competitive Advantage in the Hard Disk Drive Industry. Stanford: Stanford University Press.

McKinlay, A. and J. Zeitlin. 1986. The meanings of organizational prerogative: industrial relations and the organization of work in British engineering, 1880-1939. Business History 31, 32-47.

Malecki, E. J. 1987. The R\&D location of the firm and creative regions: a survey. Technovation 6, 205-22.

Malmberg, A. and P. Maskell. 2001. The elusive concept of localization economies: towards a knowledge-based theory of spatial clustering. Paper presented at the Association of American Geographers Annual Conference, New York, February/March 2001.

Maskell, P., H. Eskelinen, I. Hannibalsson, A. Malmberg and E. Vatne. 1998. Competitiveness, Localised Learning and Regional Development. London: Routledge

Morgan, G. 1997. Images of Organization. Thousand Oaks CA: Sage

Whitley, R. 1992. European Business Systems: Firms and Markets in their National Contexts. London: Sage Publications.

Nonaka, I. and H. Takeuchi. 1995. The Knowledge-Creating Company: How Japanese Companies Create the Dynamics of Innovation. Oxford: Oxford University Press.

O'Reilly, C.A. 1989. Corporate culture considerations based on an empirical study of high growth firms in Silicon Valley. Economia Aziendale, Volume III, 3.

Piore, M. and C.F. Sabel. 1984. The Second Industrial Divide: Possibilities for Prosperity. New York: Basic Books.

Porter, M.E. 1998. On Competition. Boston: Harvard Business School Press.

Porter, M.E. 2000. Locations, clusters and Company Strategy. In The Oxford Handbook of Economic Geography edited by G.L. Clark, M.P. Feldman and M.S. Gertler. Oxford: Oxford University Press.

Sahlins, M.D. 1976. Culture and Practical Reason. Chicago: Chicago University Press. 
Saxenian, A. 1994. Regional Advantage: Culture and Competition in Silicon Valley and Route 128. Cambridge, MA: Harvard University Press.

Sedgwick, P. 1999. Rationality. In Key Concepts in Cultural Theory edited by A. Edgar and P. Sedgwick. London: Routledge.

Silverman, D. 1970. The Theory of Organizations. London: Heinemann.

Simon, H. 1955. A behavioral model of rational choice. Quarterly Journal of Economics $69,99-118$.

Simon, H. 1956. Rational choice and the structure of environments. Psychology Review 63, 129-138.

Simon, H. 1987. Bounded rationality. In The New Palgrave Dictionary of Economics edited by J. Eatwell, M. Milgate and P. Newman. London: Macmillan.

Simon, H. 1997. Models of Bounded Rationality: Empirically Grounded Reason. Cambridge MA: MIT Press.

Smith, A. 1776. The Wealth of Nations (1910 edition). London: Dent.

Storper, M. 1997. The Regional World: Territorial Development in a Global Economy. New York: The Guildford Press.

Teece, D. J. 2000. Managing Intellectual Capital. Oxford: Oxford University Press.

Tracey, P., G.L. Clark and H. Lawton Smith. 2001. On the margin: the performance of UK SMEs in labour intensive industries. Paper presented at the Regional Studies Association Annual Conference, Gdansk, September 2001. 